\title{
Evaluation of Interview Application based on Radon System
}

\author{
Ahmad Syafiq kamil ${ }^{1}$, Ima Kurniastuti ${ }^{2}$ \\ \{ ahmadsyafiqkamil@unusa.ac.id ${ }^{1}$, ima.kurniastuti@unusa.ac.id ${ }^{2}$ \} \\ Department of Information System, Engineering Faculty, Nahdlatul Ulama Surabaya University ${ }^{1,2}$
}

\begin{abstract}
The interview process is an important process in collecting data on the development of a master plan where data collection is currently done manually. the manual data collection stage results in a delay in the analysis process. in the end, it caused a delay in the entire schedule of the project being worked on. in this study researchers designed and developed a survey application that serves to facilitate a surveyor in collecting data. Survey application design using UML consisting of usecase diagrams, sequence diagrams, and ERD. this application was also built using the django framework. This application analysis uses a library that is Radon. by using radon applications can be calculated using several indicators such as cyclomatic cycle(CC), maintability index (MI) and the risk of the application. the results of this study have been developed a survey application where this application has a low CC level, a high MI level and a low level of risk.
\end{abstract}

Keywords. Interview application, e-government, Django, radon

\section{Introduction}

Technology has touched all sides of people's lives including government services especially the regional government. Institutions in local government have directly contact with the community and need change to be more efficient by utilizing technology is called the Regional Government Work Unit or Satuan Kerja Perangkat Daerah (SKPD). However, to be able to develop a program that can accommodate all SKPD needs requires a good information system / information technology (IS/IT) master plan. Master plan represents the needs, tasks and functions related to SKPD. The making of master plan requires quitelongtime and large cost. One of process in makingof master plan is interview process to obtain detailed and comprehensive information. Interview is a form of communication between two or more people and takes place between the resource person and the interviewer.

Interview process in data collection is an important stage. Interview process is a basic process to determine work programto developing IS / IT in the medium term until long term. Incorrect or inaccurate data has an impact to master plan results. Development of work program for IS / IT is wrong or not in accordance with SKPD requirements. Data collecting will be carried out by surveyors. Data from surveyors is analysedby analyst. Theresults of analysis data will be a reference in makinga master plan of a government institution. The interview process is still done manually. But with pandemic covid- 19 situation, interview process must be in online using interview application.

This study aims to develop an interview application that uses the python language and Django framework as a web development framework [1]. The interview application was tested using a library namely radon. Radon is a library that can calculate various metrics from an application's source code [2]. Applications are tested using Cyclomatic Complexity (CC), metrics such as Line of Code (LOC), logical lines of code(LLOC) and sourcelines of code (SLOC). Thedevelopment of interview application aims to assist a surveyor and analyst in developing an SI / IT master plan in government agencies. Benefits for surveyors are easierfor a surveyorin conductinginterviews. Usingthis interview application will save time in conducting surveys. The benefit for an analyst is that the survey results obtained from a surveyor can be directly accepted without having to ask the surveyor. 


\title{
Kresna Social Science and Humanities Research
}

\author{
Proceedings of the International Conference On Ummah: \\ Digital Innovation, Humanities And Economy (ICU: DIHEc) 2020 \\ https://doi.10.30874/ksshr.62
}

\section{Research Method}

The step of research is consisted of three stages such as early phase, development phase dan evaluation phase. Early phase is consisted of literature review and requirement analysis. Development phase is consisted of design of application, design of prototype, developing application. The last phase is evaluation phase such as testing using radon. In radon, applications are tested using Cyclomatic

Complexity (CC), Maintainability Index (MI), Line of Code (LOC), logical lines of code (LLOC), source lines of code (SLOC) and Risk.

In early phase bedivided into two, namely literature review and analysis of software requirements. In the literature review stage, it discusses some literature related to interviews and the Django framework. The result of this stage is several requirements are obtained to create an interview application using the Django framework. List of language and library to making interview application is shown in Table 1. At the requirements analysis stage the researcher gathers the need to develop the application. This needs analysis is needed so that researchers can make the interview application in accordance with what is needed.

Table 1. List of language and library

\begin{tabular}{|l|l|l|l|}
\hline No & \multicolumn{1}{|c|}{ Language } & \multicolumn{1}{c|}{ Type } & \multicolumn{1}{c|}{ Explanation } \\
\hline 1 & Python & Language & programming language used \\
\hline 2 & Django & Framework & $\begin{array}{l}\text { Framework for web application based on } \\
\text { python }\end{array}$ \\
\hline 3 & HTML & Language & programming language used \\
\hline 4 & SurveyJs & Library & library used to create the interview form \\
\hline 5 & SQL & Languge & programming language used for database \\
\hline
\end{tabular}

In development stage, the researcher develops an interview application from the needs analysis that has been done. The results of the needs analysis will be processed into a visualization of a system using Unified Modeling Language (UML). The output generated from the visualization process is the Use Case diagram, Sequence Diagram and Entity Relational Diagram (ERD). Sequence diagram is a diagram that illustrates the interaction between parts that exist in the system. Flowchart of development phase is shown in Figure 1. Application is built in Django framework. Django is a high-level Python Web framework that encourages rapid development and clean, pragmatic design. Built by experienced developers, it takes care of much of the hassle of Web development, so you can focus on writing your app without needing to reinvent the wheel. It's free and open source. The advantage of using Django framework are fast, reassuringly secure and exceedingly scalable. Django was designed to help developers take applications from concept to completion as quickly as possible. Django takes security seriously and helps developers avoid many common security mistakes. Some of the busiest sites on the Web leverage Django's ability to quickly and flexibly scale [3].

In evaluationphase, the researcher done testingapplicationusingradonsystem. Radon is a library that can calculate various metrics from an application's source code. Radon has a set of functions and classes that you can call from within your program to analyze files [4]. The code metrics is used are Cyclomatic Complexity (CC), Maintainability Index (MI), Line of Code (LOC), logical lines of code (LLOC), source lines of code (SLOC) and Risk. Cyclomatic Complexity corresponds to the number of decisions a block of code contains plus 1 . This number (also called McCabe number) is equal to the number of linearlyindependent paths throughthe code. This number canbe usedas a guide when testing conditional logic in blocks. Maintainability Index is a softwaremetricwhichmeasures howmaintainable (easy to support and change) the source code is. The maintainability index is calculated as a factored formula consisting of SLOC (Source Lines Of Code), Cyclomatic Complexity and Halstead volume. It is used in several automated software metric tools which uses a shifted scale (0 to 100) derivative [5]. 


\section{Kresna Social Science and Humanities Research}

Proceedings of the International Conference On Ummah:

Digital Innovation, Humanities And Economy (ICU: DIHEc) 2020

$$
\text { https://doi.10.30874/ksshr.62 }
$$

Line of Code (LOC) has definition the total number of lines of code. Logical lines of code (LLOC) is the number of logical lines of code. Every logical line of code contains exactly one statement. Source lines of code (SLOC) is the number of source lines of code - not necessarily corresponding to the LLOC [6].

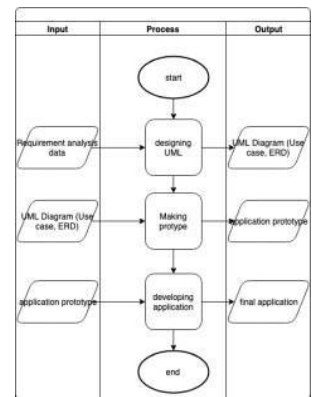

Figure 1. Flowchart in development stage

\section{Results and Analysis}

1. Requirement Analysis

In requirement analysis, user business process is shown in Figure 2. From Figure 2, there are several problems faced by users. These problems were the result of making devices that are still kept by each project manager, surveyors carryout repeatedsurveys with the aim of validatingthe results of the survey to clients, survey results data that are sometimes lost. After analyzingthe needs of researchers formulate functional needs that have been obtained from interviews with users. The functional needs are used to determine the scope of developing interview applications. There are some functional requirements of this application such as the interview application allows the project manager to create projects and organizations, the interview application allows project manager to making survey tools, the interview application allows project manager to plotting surveyors and analysts, the interview application allows the surveyor to save the results of the interview, the interview application allows the analyst to get the results of interviews from all surveys conducted by surveyors.

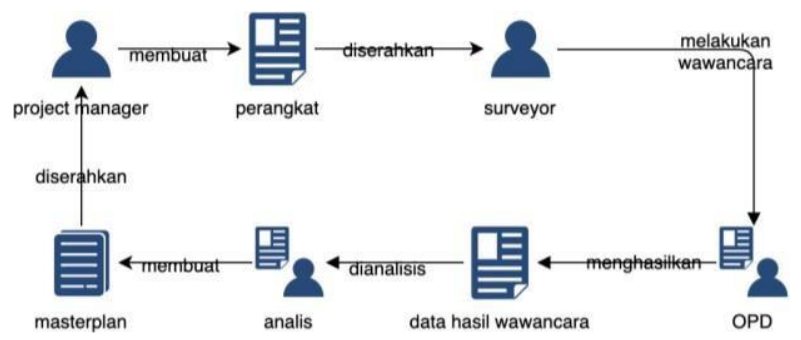

Figure 2. User Bussiness Process

2. Design of application

In this stage, researchers use Unified Modeling Language (UML) to make it easy to understand applicationwhen it developed [7]. The diagram in this study is the use case diagram, Sequence Diagram and Entity Relationship Diagram (ERD). In Figure 3 shows the use case diagram of the interview application. From Figure 3, there are three actors who use application. The case in Figure 3 is a feature in the interview application. The second diagram is sequence diagram. Sequence diagram is a diagram that illustrates the interaction between parts that exist in the system. Figure 4 (a) shows the sequence diagram for the project creation feature. The feature has the right to access is project manager. Project managers can create a project and add organizations to the create project feature. In Figure 4 (b) shows the interview set creation features of a project. In this feature a project manager can create an interview set. The interview set will be used by surveyors to surveythe organization of ongoingprojects. The next feature in sequence diagrams is the survey feature is shown in Figure 4 (c). This feature canbe accessed by a surveyor. In this feature the surveyor will access the menu to conduct surveys on the organization. 


\section{Kresna Social Science and Humanities Research}

Proceedings of the International Conference On Ummah: Digital Innovation, Humanities And Economy (ICU: DIHEc) 2020

$$
\text { https://doi.10.30874/ksshr.62 }
$$

After conducting a survey a surveyor will save the results of the survey has been done. Figure 4 (d) is a sequence diagram for the survey results feature. The actor on this feature is an analyst. An analyst can see all the survey results that have been conducted by surveyors. Figure 5 shows the entity relationship diagram of theinterview application. Thepicture alsoshowsthe relationshipbetweenthe models applied by the interview. in this applicationthere areseveral models used, such as the project manager, surveyor, analyst, and account model models. Each model is interconnected so that the application can be used.

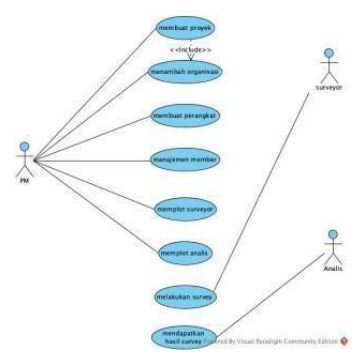

Figure 3. Use Case Diagram for interview application

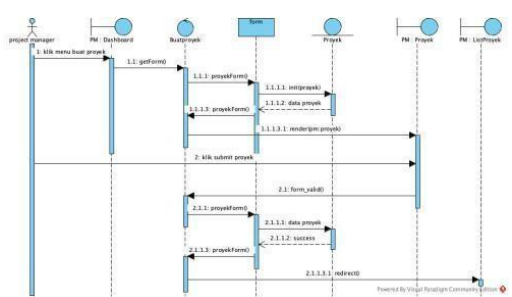

(a)

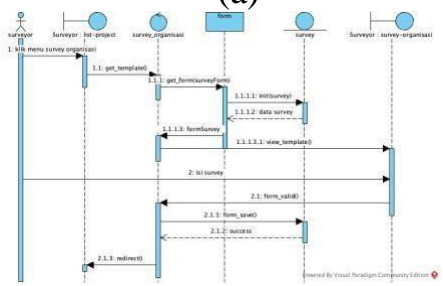

(c)

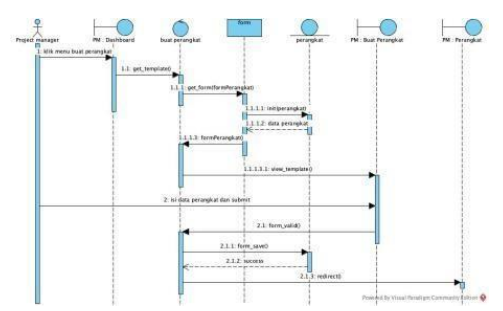

(b)

Figure 4. (a) Sequence Diagram for Create Project Feature (b) Sequence Diagram for Create Interview Set (c) Sequence Diagram for Survey Features (d) Sequence Diagram for Survey Results Features

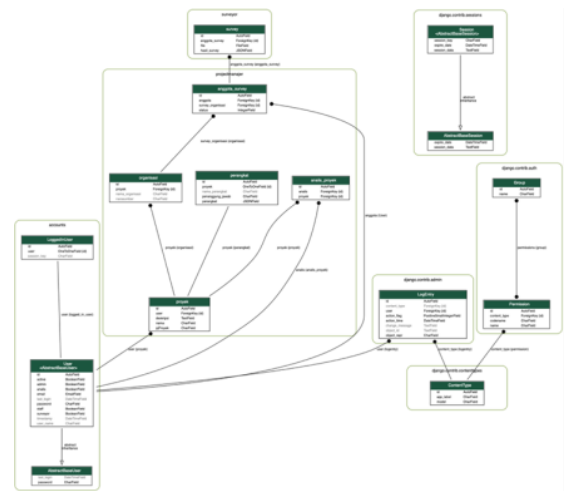

Figure 5. Entity relationship diagram interview application 


\section{Kresna Social Science and Humanities Research}

Proceedings of the International Conference On Ummah: Digital Innovation, Humanities And Economy (ICU: DIHEc) 2020 https://doi.10.30874/ksshr.62

3. Design of prototype

In this stage several prototypes will be described by the researcher. This prototype serves to assist researchers in building interview applications. Figure 6 consist of four design which Figure 6 (a) is a prototype for the create project feature, Figure 6 (b) shows prototype Create interview set, Figure 6 (c) shows prototype survey feature and Figure 6 (d) shows prototype survey result feature.

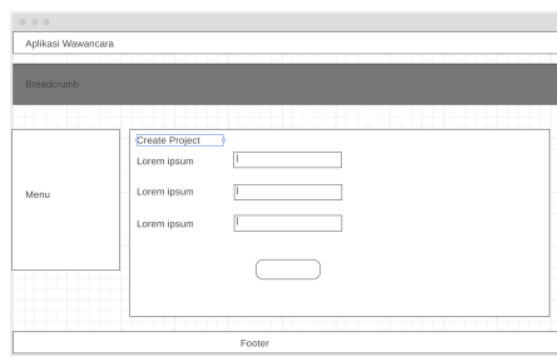

(a)

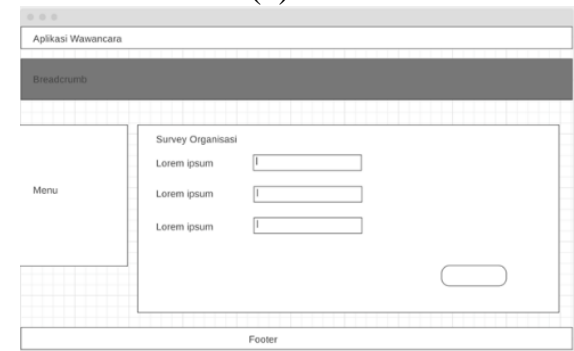

(c)

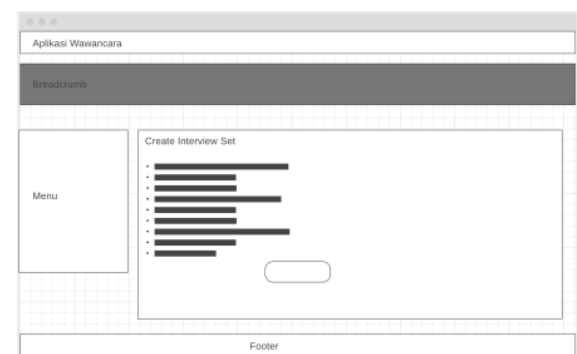

(b)

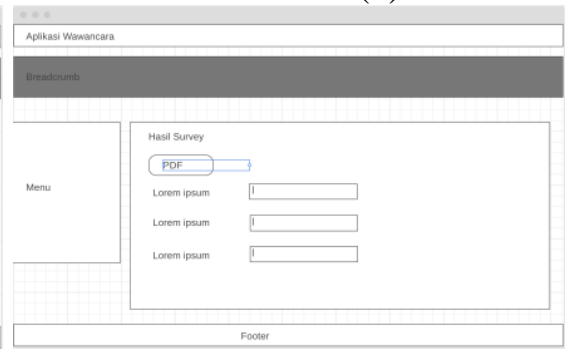

(d)

Figure 6. Design of prototype

4. Developing application

In this stage the researcher has implemented all the UML designs and prototypes that have been built. Figure 7 is a display of the application that has been built based on Figure 6. Application is built in Django framework.

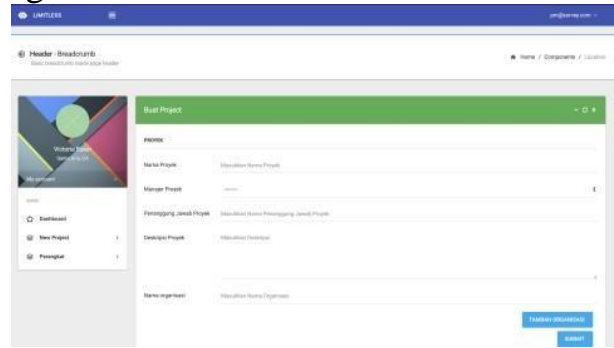

(a)

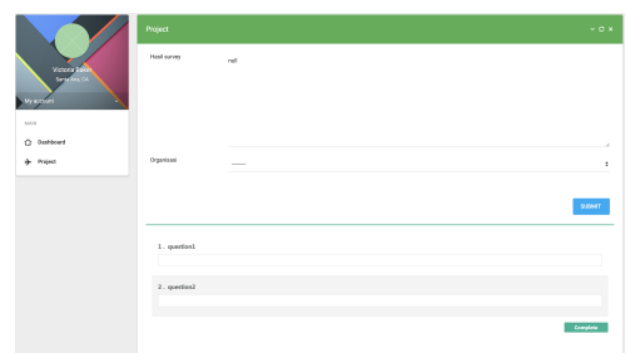

(c)

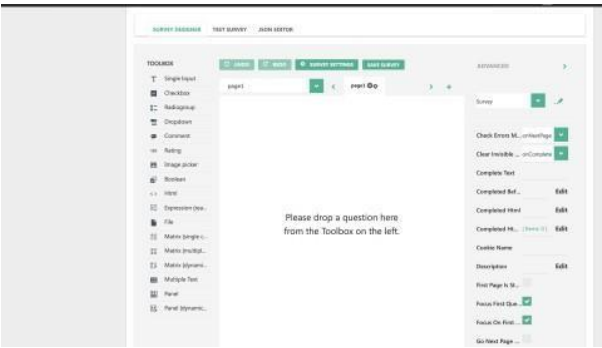

(b)

Figure 7. Result of developing application 


\section{Kresna Social Science and Humanities Research}

Proceedings of the International Conference On Ummah: Digital Innovation, Humanities And Economy (ICU: DIHEc) 2020 https://doi.10.30874/ksshr.62

\section{Evaluation phase}

At this stage the researcher will evaluate the application that has been developed. Table 2 shows the results of the evaluation conducted by Radon. From these results it can be concludedthat this applicationhas a small level of complexity. This canbe seen from the risk value obtained from each file is $\mathrm{A}$. The $\mathrm{CC}$ value in table 2 shows the average complexity value obtained from each file. Maintainability Index (MI) is a metric that can calculate the level of ease the application can be maintained. The higher the value the greater the level of simplicity. the average level of maintability obtained from this application is 81,116 . with such a level of maintability it can be concluded that this application will be very easy to maintain. While the Line of Code (LOC), logical lines of code (LLOC) and source lines of code (SLOC) are also shown in table 2.

Table 1 Evaluation Results Using Radon

\begin{tabular}{|l|l|l|l|l|l|l|}
\hline File & LOC & LLOC & SLOC & MI & CC & Risk \\
\hline accounts/views.py & 50 & 44 & 41 & 59.99 & 4.0 & $\mathrm{~A}$ \\
\hline projectmanajer/views.py & 237 & 168 & 170 & 50.45 & 1.6 & $\mathrm{~A}$ \\
\hline projectmanajer/form.py & 109 & 48 & 87 & 100 & 1.4 & $\mathrm{~A}$ \\
\hline surveyor/views.py & 69 & 53 & 54 & 100 & 1.7 & $\mathrm{~A}$ \\
\hline surveyor/form.py & 15 & 12 & 12 & 95.14 & 1.3 & $\mathrm{~A}$ \\
\hline
\end{tabular}

From all of these studies it can be concludedthat the interviewapplication has beendeveloped. The application development has features for makingprojects andorganizations, makinginterviewtools that can be used to conduct surveys, surveyor features conducting surveys using interview tools that have been made by the project manager and survey results features that can be used by analysts as data in making a master plan. Researchers have also tested the application in white box using Radon. The results obtained from Radon is that this application has a low level of complexity with a level of complexity that is A. This application also has a fairly high level of maintainability with an average value of 81,116 .

\section{Conclusion}

This study aims to develop a website-based interview application with the radon evaluation system. This research consists of several stages, namely the early phase, development phase and evaluation phase. Literature review and analysis of software requirements are included in the early phase. The development phase consists of a design of application, design of prototype and developing application. For evaluation phase using the radon system which consists of Cyclomatic Complexity (CC), Maintainability Index (MI), Line of Code (LOC), Logical lines of code (LLOC), Source lines of code (SLOC). Based on the results of the radon evaluation, it was found that the interview application had a small level of complexity and was easy to maintain.

\section{Reference}

[1] H. A. Rusdiana and M. Irfan, Sistem Informasi Manajemen. Bandung: CV Pustaka Setia, 2014.

[2] R. S. Pressman, Software engineering: a practitioner's approach, 7th ed. New York: McGraw-Hill Higher Education, 2010.

[3] "Django" [Online]. Available: https://www.djangoproject.com/ [Accessed : 16-Aug-2020].

[4] "Using Radon Programmatically"[Online]. Available: https://radon.readthedocs.io/en/latest/api.html. [Accessed: 16-Augt-2020].

[5] Paul Omand and Jack Hagemeister. "Metrics for assessing a software system's maintainability". Proceedings International Conference on Software Mainatenance (ICSM), 1992. 


\section{Kresna Social Science and Humanities Research}

Proceedings of the International Conference On Ummah: Digital Innovation, Humanities And Economy (ICU: DIHEc) 2020 https://doi.10.30874/ksshr.62

[6] Don M. Coleman, Dan Ash, Bruce Lowther, Paul W. Oman. Using Metrics to Evaluate Software System Maintainability. IEEE Computer 27(8), 1994.

[7] "What is Unified Modeling Language (UML)?" [Online]. Available: https://www.visualparadigm.com/guide/uml-unified-modeling-language/what-is-uml/. [Accessed: 05-Sep-2019]. 